\title{
STUDY OF PROBLEMS AND DISORDERS IN DENTAL CLINICS ARCHITECTURAL DESIGN
}

\author{
Mojhgan Pasaeian \\ Master of Architecture, Art and Architecture of Islamic Azad University Central Tehran Branch, Iran \\ mojipasa@hotmail.com \\ Dr.Mohammad Saeidi \\ Assistant Professor of Anesthesiology, Qom University of Medical Sciences, Iran \\ dr.msaeidi@hotmail.com
}

\begin{abstract}
Hasty process, outlawed development and principles of architecture of dental clinics in most cities, has changed the situation in such a way that the dental clinics, special new build clinics they are new physical and aesthetic architecture have been significant problems in dental clinic cannot give material and physical needs of peoples the answer them dignity and also cannot have a sense of relaxation in a space of their spiritual needs and embrace. In this paper, by examining the validity of the staff and patients of dental clinics we explain and we will prove that the challenges of architecture and planning in the design of dental clinics in Tehran and other big cities as the model cases that compliance with them, a consideration of the dignity of patients and staff of dental clinics in mental peace be maintained as well as the proper use of science and new development.
\end{abstract}

Keywords: architecture, dentistry, clinic, design, Tehran

\section{INTRODUCTION}

Like most arts and skills in human society, architecture is also formed on the basis of specific principles and values. These principles and values originate from way of thinking and cultural values governing the society and at the same time, they are influenced by environmental and climatic conditions, economic conditions, political and other issues. Hasty process, development outside the standards and indifference to the principles of architecture have caused a profound change in dental clinics in most cities of the country. In these circumstances, these clinics, in particular the newly built clinics, are suffering from significant problems in terms of aesthetic and physical characteristics, so that they cannot respond to the physical and material needs and do not have a peaceful and comfortable atmosphere for patients. In this article, we will examine the challenges and problems of architecture and planning in the design of dental clinics in Tehran, which is one of the challenges of the healthcare system. Then, the patterns are provided by which the dignity of patients and staff will be retained in the dental clinic and science and new developments also be used.

\section{METHOD}

After reviewing the articles and original research and interviews with staff and patients in the dental clinic, a questionnaire with ten questions below was designed:

1. Does the architectural design of the entrance and lobby give the sense of presence in a dental clinic?

2. Does the architectural design of secretarial service, waiting room and cashier is suitable?

3. Does the architecture design of waiting space is suitable?

4. Does the architectural design of dentist's workroom is suitable?

5 . Does the radiology space is suitable?

6. Do the administrative and support spaces are suitable?

7. Do the commercial spaces professionally designed?

8. Does the entertainment place for children is suitable? 
9. Does the lighting is suitable?

10. Is there adequate ventilation due to the bad smell of the dentistry materials?

And the responses were divided by the four following options:

Yes, it is good - average - no, it is poor - No comment

Ten dental clinics in different districts of Tehran were selected for the survey and a total of one hundred staff and one hundred patients in dental clinics responded to questions.

\section{DATA ANALYSIS METHOD}

The obtained data were analyzed using SPSS 13. The quantitative data are shown as the average and standard deviation and the qualitative data are shown as the frequency. Chi-square test, and quantitative variables of t-test was used to compare both qualitative and quantitative data between the two groups in case of following the normal distribution. And the equivalent nonparametric tests were used in case of non-compliance with the normal distribution. The level of significance was set at 0.05 .

\section{HOW TO COMPLY ETHICAL ISSUES:}

1. Explain the objectives of the plan

2. Hiding the name and location of respondents

3. Compliance with design partners material and intellectual rights

\section{RESULTS}

A total of 200 patients, 100 patients and 100 staff, completed the questionnaire.

Questionnaire

\begin{tabular}{|c|c|c|c|c|}
\hline Questions & $\begin{array}{l}\text { Yes, it } \\
\text { is } \\
\text { good }\end{array}$ & average & $\begin{array}{l}\text { no, it } \\
\text { is poor }\end{array}$ & No comment \\
\hline $\begin{array}{l}\text { 1. Does the architectural design of the entrance and } \\
\text { lobby give the sense of presence in a dental clinic? }\end{array}$ & & & & \\
\hline $\begin{array}{l}\text { 2. Does the architectural design of secretarial service, } \\
\text { waiting room and cashier is suitable? }\end{array}$ & & & & \\
\hline $\begin{array}{l}\text { 3. Does the architecture design of waiting space is } \\
\text { suitable? }\end{array}$ & & & & \\
\hline $\begin{array}{l}\text { 4. Does the architectural design of dentist's workroom } \\
\text { is suitable? }\end{array}$ & & & & \\
\hline 5. Does the radiology space is suitable? & & & & \\
\hline $\begin{array}{l}\text { 6. Do the administrative and support spaces are } \\
\text { suitable? }\end{array}$ & & & & \\
\hline 7. Do the commercial spaces professionally designed? & & & & \\
\hline $\begin{array}{l}\text { 8. Does the entertainment place for children is } \\
\text { suitable? }\end{array}$ & & & & \\
\hline 9. Does the lighting is suitable? & & & & \\
\hline $\begin{array}{l}\text { 10. Is there adequate ventilation due to the bad smell of } \\
\text { the dentistry materials? }\end{array}$ & & & & \\
\hline
\end{tabular}

The age distribution of respondents is given in Table 1. As can be seen, the two groups were similar in terms of age distribution and there isn't any significant difference between the two groups $(\mathrm{p}=0.423)$.

Table 1. The age distribution of respondents

\begin{tabular}{|l|c|c|}
\hline & Mean \pm standard deviation (Year) & p-value \\
\hline Staff & $39 / 3 \pm 13 / 2$ & \multirow{2}{*}{$0 / 423$} \\
\hline Patients & $43 / 1 \pm 15 / 6$ & \\
\hline
\end{tabular}


The age distribution of respondents is also given in Table 2 and there isn't any significant difference between the two groups $(\mathrm{p}=0.988)$.

Table 2. The age distribution of respondents

\begin{tabular}{|l|c|c|c|}
\hline & Man & Woman & p-value \\
\hline Staff & 52 & 48 & \\
& $(\% 50)$ & $(\% 50)$ & \multirow{2}{*}{$0 / 988$} \\
Patients & 53 & 48 & \\
& $(\% 50)$ & $(\% 50)$ & \\
\hline
\end{tabular}

The results of the questionnaire presented separately in Tables 3 to 12 .

Table 3 along with chart: "does the architectural design of the entrance and lobby give the sense of presence in a dental clinic?"

\begin{tabular}{|l|r|r|r|r|}
\hline Number of responses & Yes, it is good & Average & No, it is poor & No comment \\
Description & 14 & 25 & 54 & 7 \\
\hline Staff & 11 & 26 & 61 & 2 \\
\hline Patient & 25 & 51 & 115 & 9 \\
\hline total & $\% 5.12$ & $\% 5.25$ & $\% 5.57$ & $\% 5.4$ \\
\hline Final percent & & & & \\
\hline
\end{tabular}

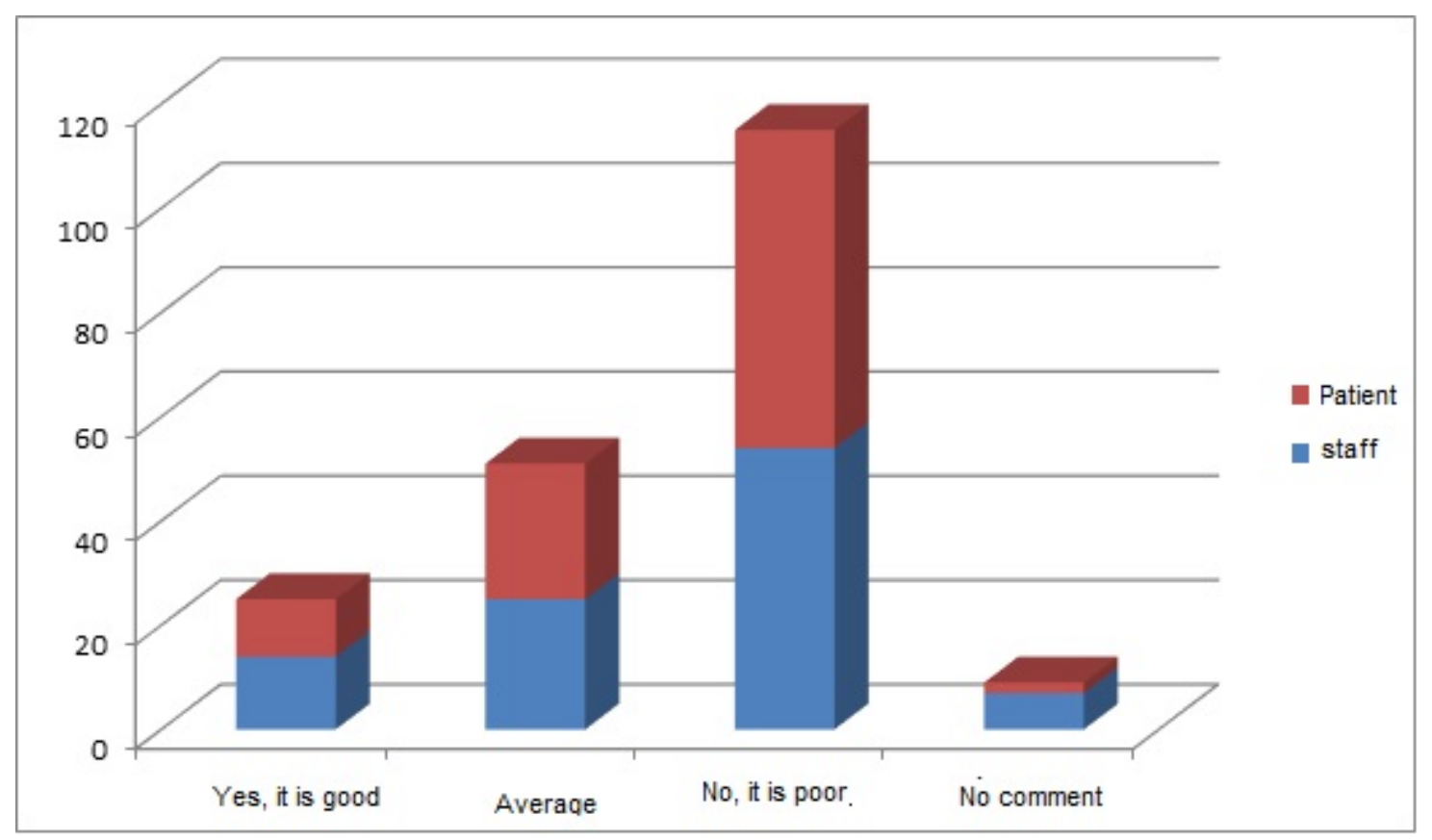


Table 4 along with chart: "does the architectural design of secretarial service, waiting room and cashier is suitable?"

\begin{tabular}{|l|r|l|r|r|}
\hline Number of responses & Yes, it is good & Average & No, it is poor & No comment \\
Description & & & & \\
\hline Staff & 10 & 22 & 63 & 5 \\
\hline Patient & 8 & 34 & 57 & 6 \\
\hline total & 18 & 56 & 120 & $\% 3$ \\
\hline Final percent & $\% 9$ & $\% 28$ & $\% 60$ & $\%$ \\
\hline
\end{tabular}

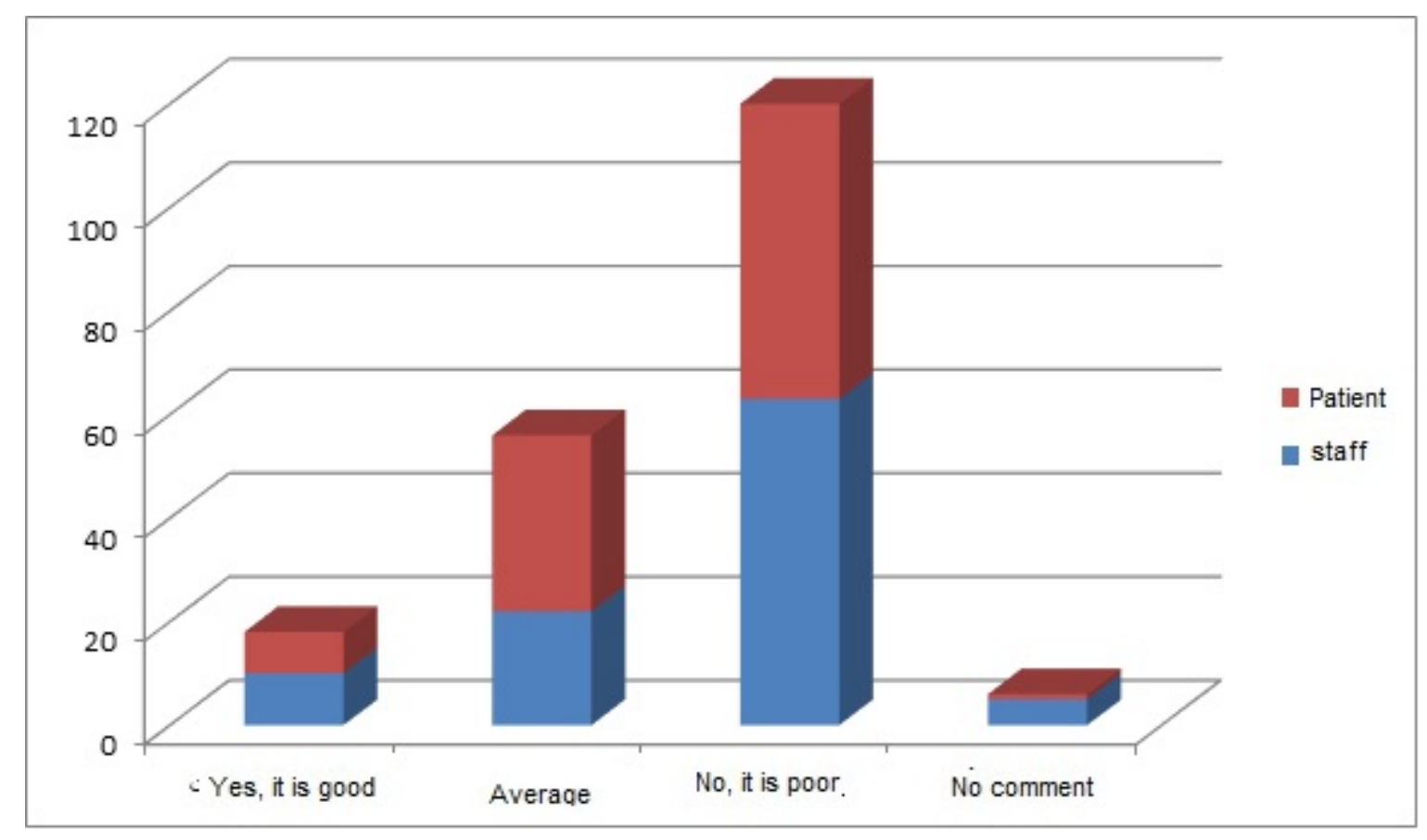


The Turkish Online Journal of Design, Art and Communication - TOJDAC August 2016 Special Edition

Table 5 along with chart: " does the architecture design of waiting space is suitable?"

\begin{tabular}{|l|r|r|r|r|}
\hline Number of responses & Yes, it is good & Average & No, it is poor & No comment \\
Description & & & & \\
\hline Staff & 15 & 28 & 54 & 3 \\
\hline Patient & 8 & 33 & 59 & 0 \\
\hline total & 23 & 61 & 113 & 3 \\
\hline Final percent & $\% 5.11$ & $\% 5.30$ & $\% 5.56$ & $\% 5.1$ \\
\hline
\end{tabular}

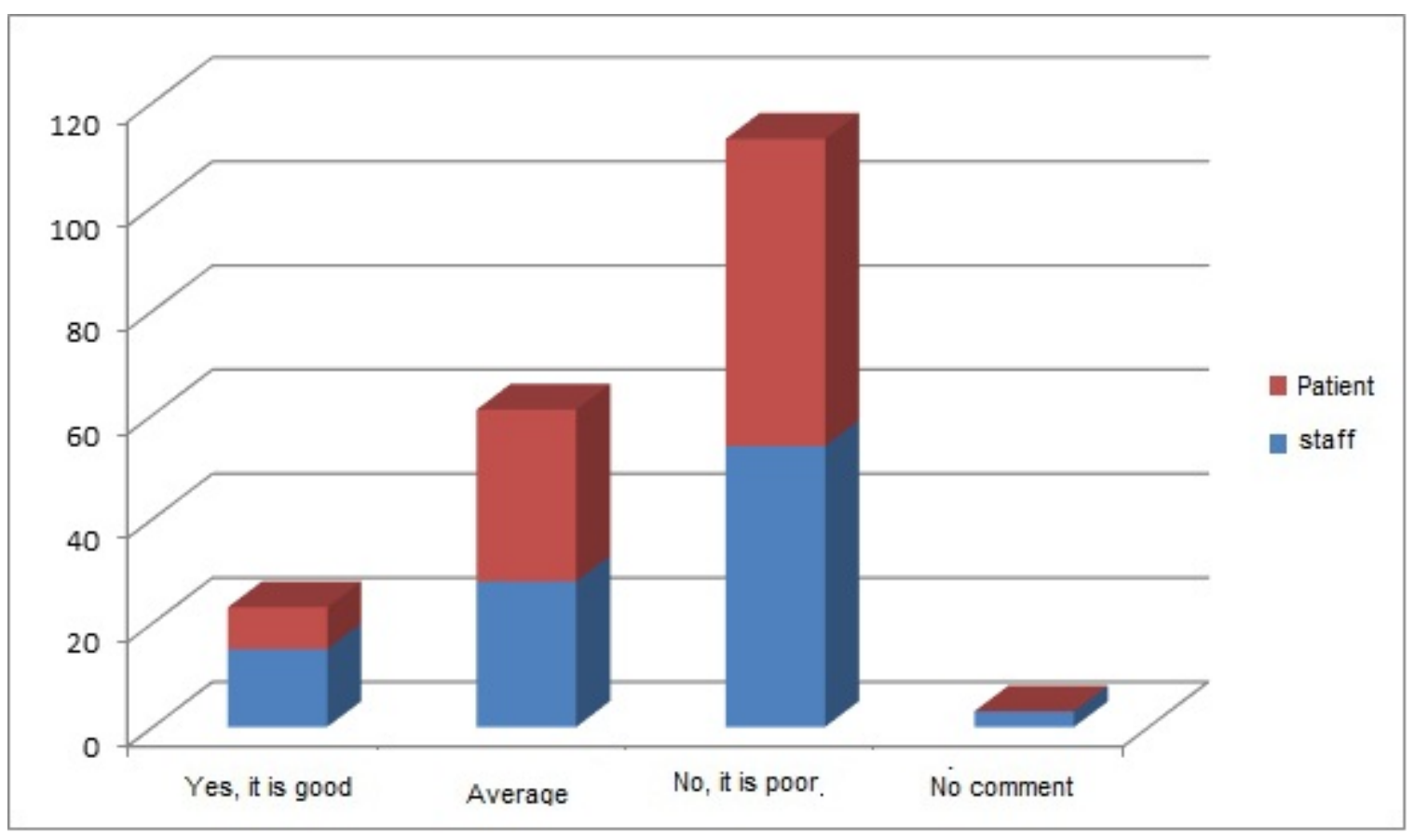


Table 6 along with chart: "does the architectural design of dentist's workroom is suitable??"

\begin{tabular}{|l|r|r|r|r|}
\hline Number of responses & Yes, it is good & Average & No, it is poor & No comment \\
Description & & & & \\
\hline Staff & 54 & 33 & 14 & 1 \\
\hline Patient & 67 & 25 & 5 & 1 \\
\hline total & 115 & 58 & 25 & $\% 1$ \\
\hline Final percent & $\% 5.57$ & $\% 24$ & $\% 5.12$ & $\% 12$ \\
\hline
\end{tabular}

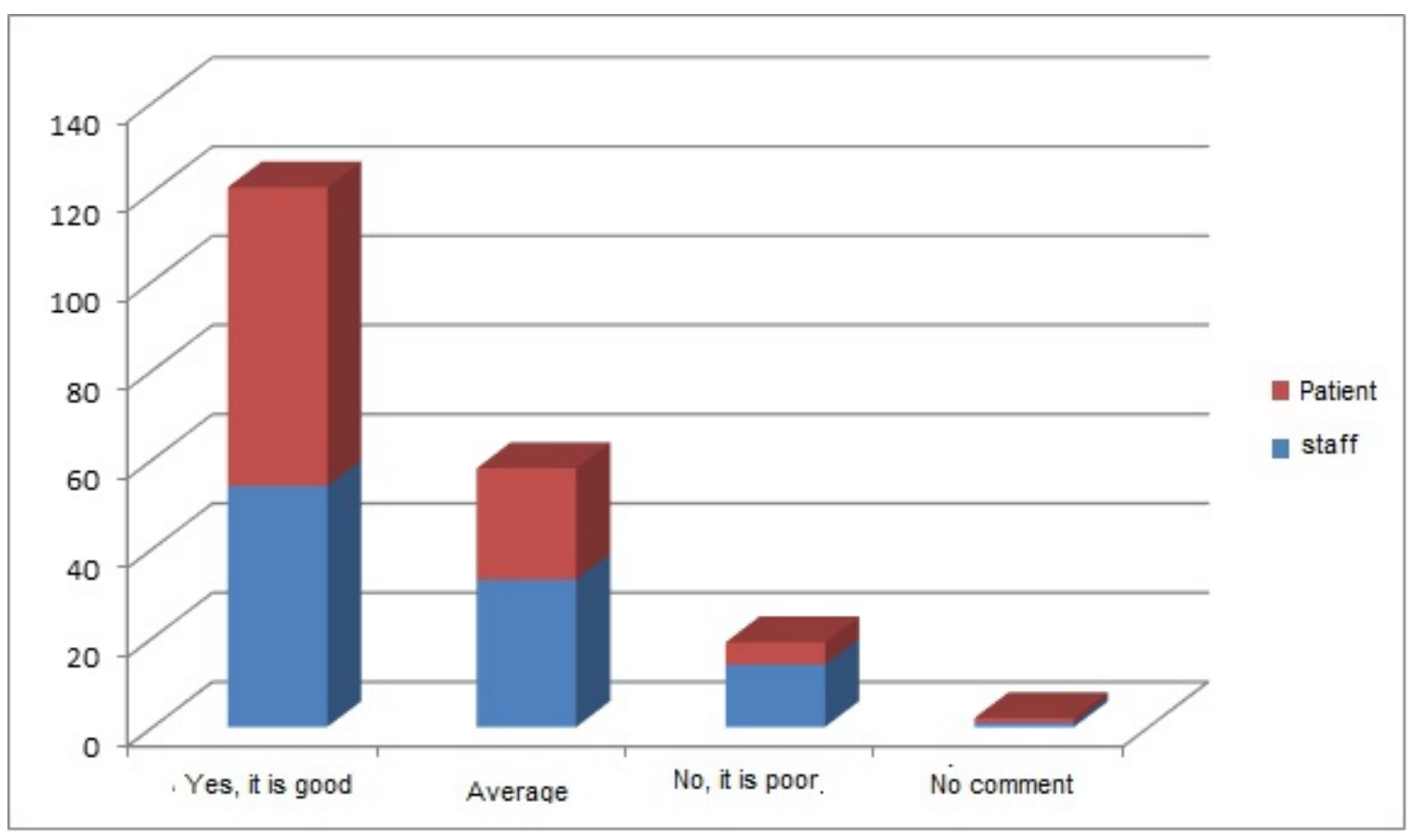


Table 7 along with chart: "does the radiology space is suitable?"

\begin{tabular}{|l|r|r|r|r|}
\hline Number of responses & Yes, it is good & Average & No, it is poor & No comment \\
Description & & & & \\
\hline Staff & 9 & 47 & 42 & 2 \\
\hline Patient & 5 & 20 & 63 & 12 \\
\hline total & 14 & 67 & 105 & 14 \\
\hline Final percent & $\% 7$ & $\% 33.5$ & $\% 52.5$ & $\% 7$ \\
\hline
\end{tabular}

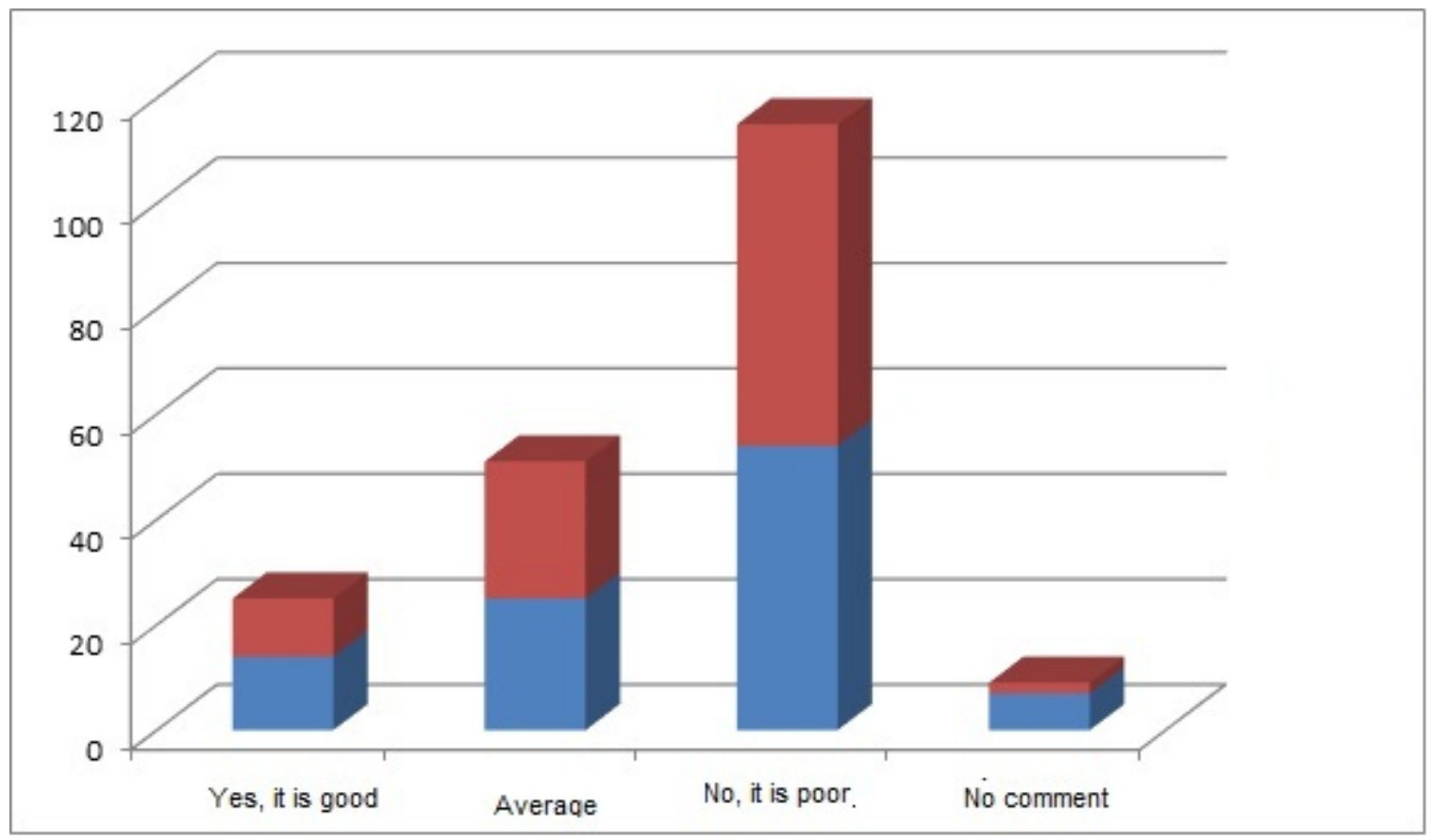


Table 8 along with chart: "do the administrative and support spaces are suitable?"

\begin{tabular}{|l|r|r|r|r|}
\hline Number of responses & Yes, it is good & Average & No, it is poor & No comment \\
Description & & & & \\
\hline Staff & 29 & 49 & 18 & 4 \\
\hline Patient & 23 & 42 & 22 & 13 \\
\hline total & 52 & 91 & 40 & 17 \\
\hline Final percent & $\% 26$ & $\% 40.5$ & $\% 20$ & $\% 8.5$ \\
\hline
\end{tabular}

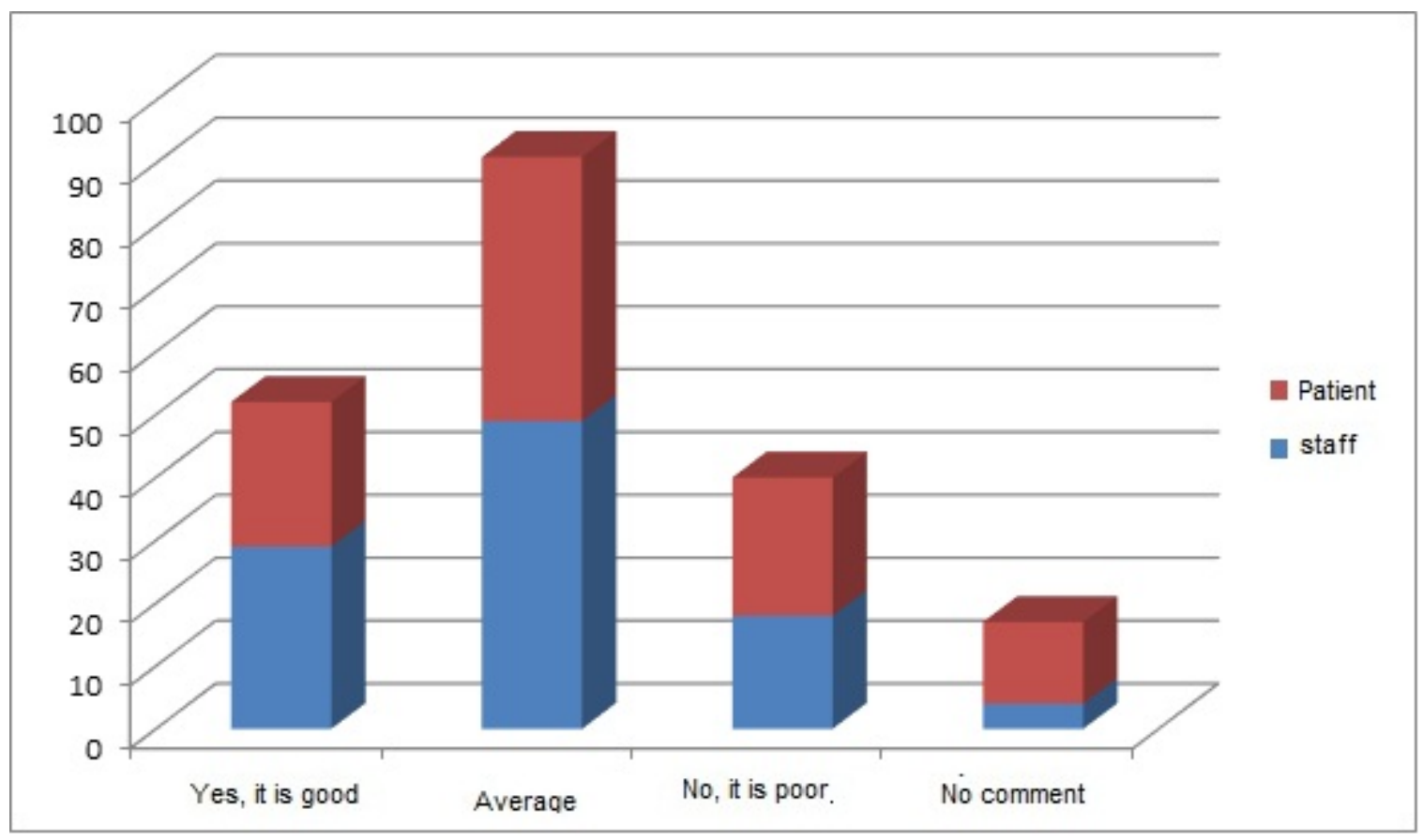


Table 9 along with chart: "do the commercial spaces professionally designed?"

\begin{tabular}{|l|r|r|r|r|}
\hline Number of responses & Yes, it is good & Average & No, it is poor & No comment \\
Description & & & & \\
\hline Staff & 34 & 31 & 30 & 5 \\
\hline Patient & 26 & 41 & 23 & 10 \\
\hline total & 60 & 72 & 53 & 15 \\
\hline Final percent & $\% 30$ & $\% 36$ & $\% 26.5$ & $\% 7.5$ \\
\hline
\end{tabular}

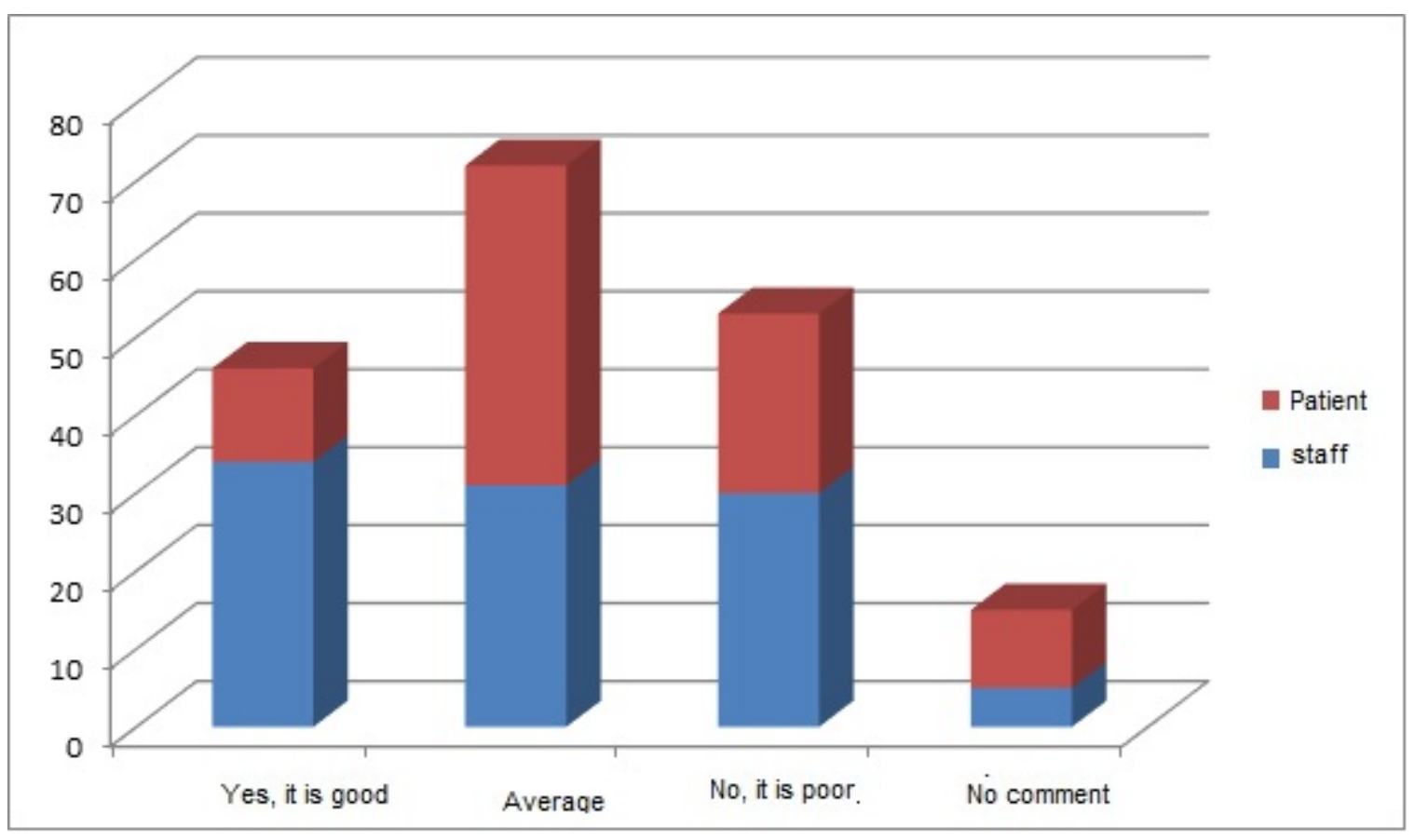


Table 10 along with chart: "does the entertainment place for children is suitable?"

\begin{tabular}{|l|r|r|r|r|}
\hline Number of responses & Yes, it is good & Average & No, it is poor & No comment \\
Description & & & & \\
\hline Staff & 4 & 30 & 58 & 8 \\
\hline Patient & 1 & 19 & 57 & 23 \\
\hline total & 5 & 49 & 115 & 31 \\
\hline Final percent & $\% 2.5$ & $\% 24.5$ & $\% 57.5$ & $\% 15.5$ \\
\hline
\end{tabular}

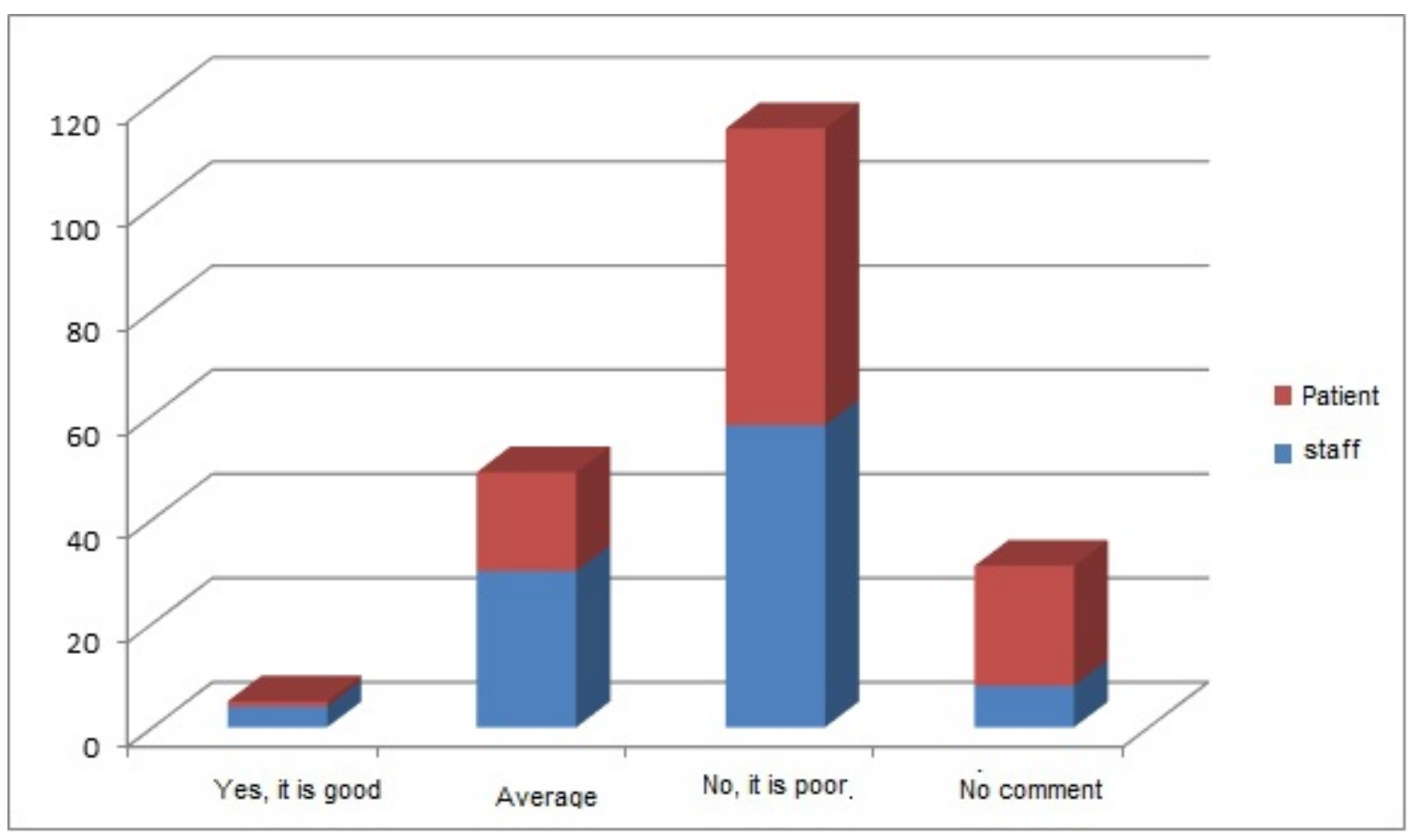


Table 11 along with chart: "does the lighting is suitable?"

\begin{tabular}{|l|r|r|r|r|}
\hline Number of responses & Yes, it is good & Average & No, it is poor & No comment \\
Description & & & & \\
\hline Staff & 21 & 48 & 28 & 3 \\
\hline Patient & 36 & 43 & 16 & 5 \\
\hline total & 57 & 91 & 44 & 8 \\
\hline Final percent & $\% 28.5$ & $\% 40.5$ & $\% 22$ & $\% 4$ \\
\hline
\end{tabular}

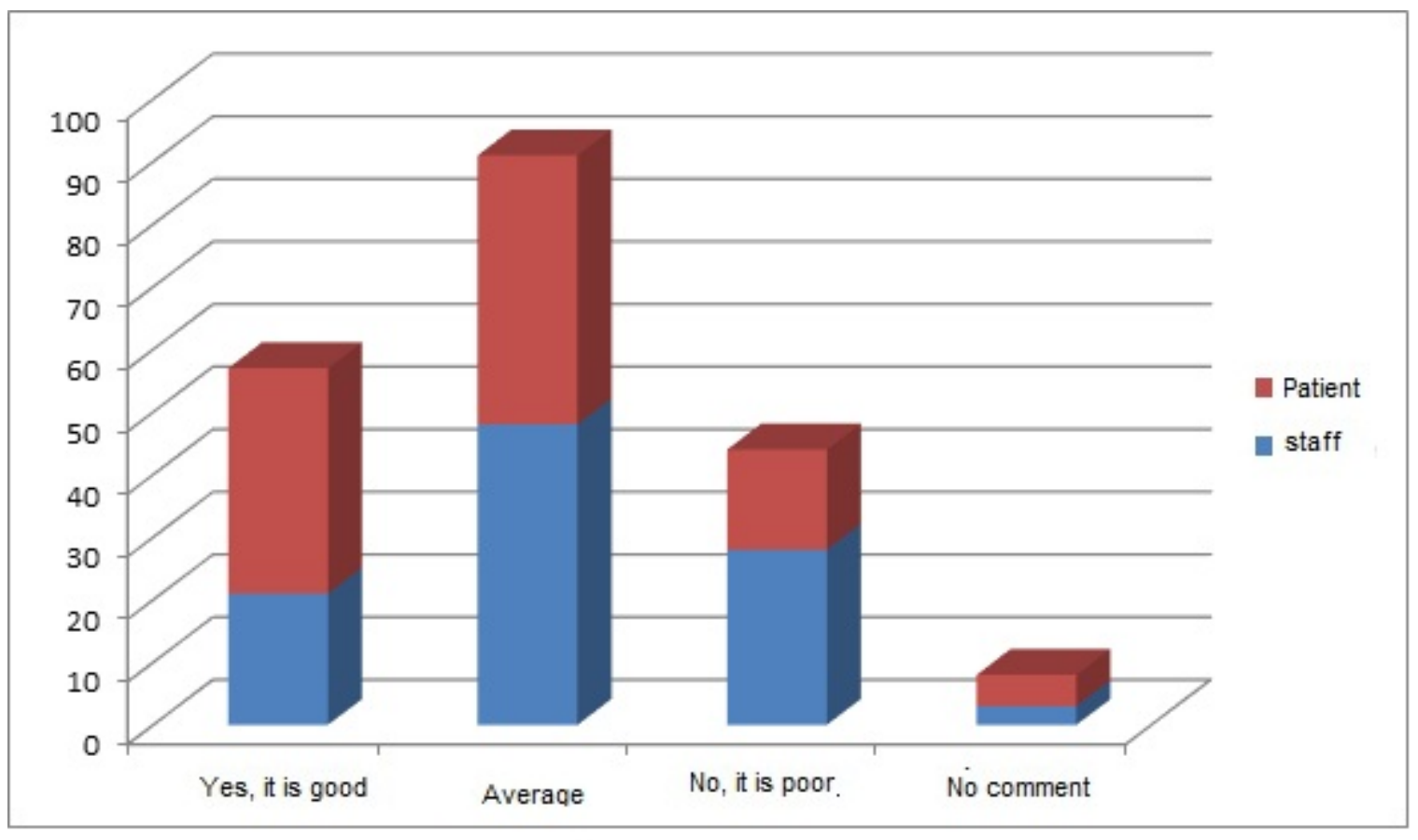


Table 12 along with chart: "is there adequate ventilation due to the bad smell of the dentistry materials?"

\begin{tabular}{|l|r|r|r|r|}
\hline Number of responses & Yes, it is good & Average & No, it is poor & No comment \\
Description & & & & \\
\hline Staff & 17 & 32 & 49 & 2 \\
\hline Patient & 18 & 13 & 68 & 1 \\
\hline total & 35 & 45 & 117 & 3 \\
\hline Final percent & $\% 17.5$ & $\% 22.5$ & $\% 58.5$ & $\% 5.1$ \\
\hline
\end{tabular}

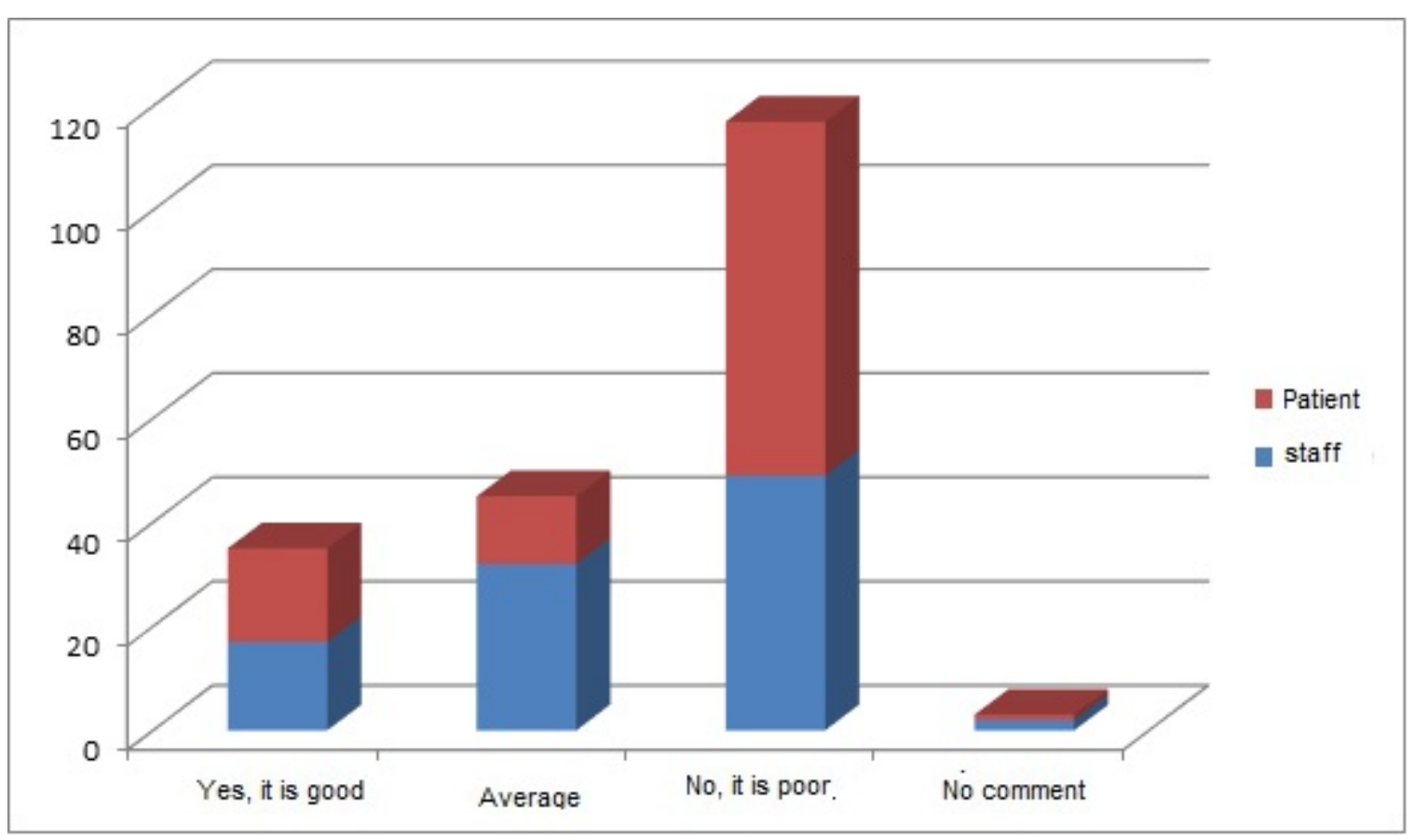




\section{DESCRIPTION}

After reviewing the questionnaires that were completed by staff and patients, it was observed that, in most cases, there is dissatisfaction with the architectural design and physical spaces which are as follows:

1. The entrance and lobby does not make any sense of presence in a dental clinic.

2. The secretary and the queue systems and cashier are stereotypes.

3. The public waiting room space and each sector do not have a role in reducing stress and relaxing the patients.

4. Workroom of dentists in most clinics is very horrific and inappropriate.

5. The radiology space is an unprofessional space and often placed in the corner of warehouse.

6. Administrative and support spaces are not designed properly.

7. Commercial spaces were not designed for professionals.

8. There isn't any place to play and entertain children.

9. There is no relaxing lighting.

10. There is no proper ventilation due to the bad smell of dental materials.

In a time when everyone acknowledges the fierce competition between dental clinics. Undoubtedly, patients would choose a dentist that is comfortable and more relaxed. To be sure, there are some chairs and a few tables for relatives and patient himself in any dental clinic. But does any dental center can be considered a center with proper waiting room?

Costs related to the construction of a dental clinic is very high. Therefore, project management and design in a complex is essential. Minimizing the project costs and staff should be a priority. Design project would include intensive consultation with customers, dentists, engineers, architects, designers and medical experts during an early stage in order to eliminate the risk of unfavorable investment decisions and unwanted increase in operation costs. The importance of collaboration between architects, engineers, managers and technicians cannot be overemphasized. After designing the entire project, interior design for a dental clinic must be designed and a place fit for service, systems engineering and medical equipment to be considered.

Throughout history, architecture and urban planning have played a significant role in social life of citizens and human beings always tried to dominate the environment in order to achieve peace and stability. However, such a domination do not exist in dental clinics; and there is an incision and separation between spaces and, therefore, sense of belonging to space and place has been lost. Now if the psychological security of staff and patients in a dental clinics be considered as one of the fundamental aspects of architecture and how to make a dental clinic, we find that the role of architectural design in today's dental clinics is suffering from confusion, chaos and turmoil.

If dental clinics are willing to change, this change must be initiated with universities, dental schools and dental education system. Dental Clinic is a medical center that specializes in multiple disciplines of dental hygiene. Specialization among dentists has paved the way for the creation of therapeutic and diagnostic centers that provide extensive services. The advantage of this center is to reduce patient wait times and better access to diagnosis and treatment, without visiting a doctor. The advantage of the centers for dentist is allocation of more regular working hours and the ability to exchange and benefit from the experiences of other dentists.

The items listed require a suitable space that is designed according to the needs of the consumer. Appropriate size and arrangement of spaces would be a great help to meet the needs of clients. The design of such projects requires intensive consultation with customers, dentists, engineers, and experts in hospitals and clinics, and therefore, it would not be unusual, if the design take a lot of time.

Before designing any materials should be considered characteristics. If you just say "dental centers due to their nature and theme must have a special atmosphere for ideal performance of dentists", we're talking incomplete. In fact, the atmosphere of a dental center is not simply a place a container with the possibility of specific functions for dentists and its design is not limited by the equipment, furniture and dentists functions among several walls. In a perfect design, creating a favorable and efficient 
environment is a multiple interactive between the constituent elements of a space, which mean the people and objects that are associated with the space and the function that is intended for that space. Each generate several different parameters in its proper shape. From this perspective, the features of a dental clinic are as follows:

- A safe, beautiful and clean building.

- Innovative and exciting environment, and open to patients and staff.

- Flexibility in the face of future changes in physical relationships, materials, equipment over time and in accordance with international standards.

- Competitiveness in energy efficiency (particular attention to the choice of materials and heating and cooling systems and lighting).

- Easy physical accessibility for people with disabilities.

- Ability to meet the physical and spiritual needs of patients.

- Quick and easy access to urban street networks and public transport.

You may have heard that a dentist in Berlin was able to turn his clinic into the happiest place on earth. In this clinic, patients forget their fear of pain and can even be entertained. The waiting room is designed by orange color, beautiful seats, eye-catching paintings and a lovely fireplace. In the time spent in the waiting room, patients can use the Internet, rather than thinking about their pain and stress and they can be entertained by various video games. Medical staff spend many hours at the clinic, so interior design is very important to create a happy mood for them and patients. Patients usually spend some time on the dental unit, so the design can be effective in their assessment about the clinic environment. Moreover, the interior design will be effective in maintaining a happy mood and reduce fatigue and boredom of long work in a closed environment.

\section{DESIGN PRINCIPLES OF DENTAL CLINIC}

In general, dental clinic spaces are divided into four sections including client space, office space, the main space and logistics and support.
A. Clients spaces:
1. Entrance
2. Patient waiting
3. Children waiting
4. Health facilities

B. - Office space:

1. Reception

2 office rooms (generic)

3. Archive

4. Dentist office

5. Educational space

C. The main space

1 adult dental clinic

2. Orthodontic dental clinic

3. Periodontics dental clinic

4. Endo dental clinic

5. Restorative dental clinic

6. Prosthetic dental clinic

7. Oral and Maxillofacial Surgery Clinic

8. Operating room for Oral and Maxillofacial Surgery equipped with anesthesia facilities

9. The pediatric dental clinic 
10 pediatric dental operating room equipped with anesthesia

11. Recovery

12. The sector for sterilization

13. Laboratory

14. Radiology

D. Logistics and support:

1. Break room and kitchen

2. Compartments for cleaning textile

3. The health facility for staff

4. Public Storage

5. Storage for grinding up waste

6. Installations

7. Cleaning room

8. A place for unloading the goods

Apart from client's spaces, all rooms must be in a safe area (away from any pollution). These spaces are not limited to large clinics and all dental clinics must have such areas in an appropriate scale. The number and type of clinic is determined according to the covered population and oral health care policies. The treatment room or space must be equipped with adequate and appropriate tools.

Diagnosis and treatment may be done in a room that is equipped with the dental unit. Sometimes, administrative tasks be done in the same space. However, these functions must be physically separated from the medical section. Depending on the design selected, by placing the administrative area along with partition, this space should have a capacity as much as a wheelchair or a stretcher. When a treatment space is usable for all people, even people with disabilities, it can be said that architectural design has the perfect features. Inclusion of at least one enclosed office space helps to meet the special needs or anxiety in patients.

\section{BORDER IN DESIGN}

\section{A. Single room}

In designing a single room, all the services and equipment needed for are merged in order to perform diagnosis and treatment. Single room would be appropriated for when:

1. There are only two seats for welfare facilities

2. A dynamic space can promote quality design.

3. The dental clinic should create a private space between the dentist and the patient.

4. Carrying capacity for stretcher (for emergency patients during treatment or when the patient is experiencing cardiac arrest, etc.) or wheelchair is necessary.

5. Aspects of individual dental office is 16 square meters.

\section{B. open plan}

In this design, the type of branches and location of the room will be changed and the spaces be separated by some tall partitions. Administrators space located in the front end of each unit should be separated from the treatment section by cabinets and panels. Office space can be seen in the main axis and has access to both sides. Fixed furniture can create a visual barrier between private space of patient and public hallway. Shelves of public facilities and X-ray monitor can be seen in the hallway in order to provide services to both sides. The benefits of open plan offices include the following:

1. The spatial efficiency

2. Benefits in economic aspects (the use of common equipment)

3. Environment more suitable for teaching and monitoring of dental students

4. Convenient and easy access in order to collect dirty instruments for sterilization through main access to the internal circulation corridor.

However, in some cases, the open plan be applied in the design, but the separator partition do not use in the treatment spaces. In this case, the treatment environment loses its privacy; however, if the design has the right and proper dimensions, this space would be attractive and creative. 
In the above design, the office space will be removed and the dentist should do such affairs in the therapeutic space. In addition, there should be a wheeled table (trolley) next to each unit. Remember that the dental unit should be placed in front of window and beautiful landscapes; otherwise, a beautiful painting should be used. In addition to physical therapy, the treatment space should provide space for the mental relaxation. The corridor width should not be less than $120 \mathrm{~cm}$.

\section{REFERENCES}

The Neufert Architects' Data 2014

Ghaem, G., "Common Language to build housing in Iranian Architecture", Journal of Saffeh, p. 24

Pakzad. J., "Essays on Architecture and Urbanism concepts, improved housing and quality of its expectations", fall of 1956, p. 38

Farahani jam. F., "return to traditional methods in modern architecture", Jame Jam newspapaer, Friday, April 11, 2003

Ahmadi. S., "facade or display", Daneshnameh technical magazine, Year XVIII, No. 174-175, 1953

The national system of literature and academic research

Abedi. M., "additions mode, a need forgotten", architecture and culture, November 2013

Janipour. B., "contemporary architecture of Tehran, Journal of Abadi", Number Seventeen, new era, Fall 1955, p. 32

\begin{tabular}{|c|c|c|c|c|}
\hline Question & $\begin{array}{l}\text { Yes, it } \\
\text { is } \\
\text { good }\end{array}$ & average & $\begin{array}{l}\text { no, it } \\
\text { is poor }\end{array}$ & No comment \\
\hline \multicolumn{5}{|l|}{$\begin{array}{l}\text { 1. Does the architectural design of the entrance and } \\
\text { lobby give the sense of presence in a dental clinic? }\end{array}$} \\
\hline \multicolumn{5}{|l|}{$\begin{array}{l}\text { 2. Does the architectural design of secretarial service, } \\
\text { waiting room and cashier is suitable? }\end{array}$} \\
\hline \multicolumn{5}{|l|}{$\begin{array}{l}\text { 3. Does the architecture design of waiting space is } \\
\text { suitable? }\end{array}$} \\
\hline \multicolumn{5}{|l|}{$\begin{array}{l}\text { 4. Does the architectural design of dentist's workroom } \\
\text { is suitable? }\end{array}$} \\
\hline \multicolumn{5}{|l|}{ 5. Does the radiology space is suitable? } \\
\hline \multicolumn{5}{|l|}{$\begin{array}{l}\text { 6. Do the administrative and support spaces are } \\
\text { suitable? }\end{array}$} \\
\hline \multicolumn{5}{|l|}{ 7. Do the commercial spaces professionally designed? } \\
\hline \multicolumn{5}{|l|}{$\begin{array}{l}\text { 8. Does the entertainment place for children is } \\
\text { suitable? }\end{array}$} \\
\hline \multicolumn{5}{|l|}{ 9. Does the lighting is suitable? } \\
\hline $\begin{array}{l}\text { 10. Is there adequate ventilation due to the bad smell of } \\
\text { the dentistry materials? }\end{array}$ & & & & \\
\hline & & & & \\
\hline
\end{tabular}

